\title{
Shear and foundation effects on crack root rotation and mode-mixity in moment- and force-loaded single cantilever beam sandwich specimen
}

\author{
Saseendran, Vishnu; Carlsson, Leif A.; Berggreen, Christian
}

Published in:

Journal of Composite Materials

Link to article, DOI:

$10.1177 / 0021998317749714$

Publication date:

2018

Document Version

Peer reviewed version

Link back to DTU Orbit

Citation (APA):

Saseendran, V., Carlsson, L. A., \& Berggreen, C. (2018). Shear and foundation effects on crack root rotation and mode-mixity in moment- and force-loaded single cantilever beam sandwich specimen. Journal of Composite Materials, 52(18), 2537-2547. https://doi.org/10.1177/0021998317749714

\section{General rights}

Copyright and moral rights for the publications made accessible in the public portal are retained by the authors and/or other copyright owners and it is a condition of accessing publications that users recognise and abide by the legal requirements associated with these rights.

- Users may download and print one copy of any publication from the public portal for the purpose of private study or research.

- You may not further distribute the material or use it for any profit-making activity or commercial gain

- You may freely distribute the URL identifying the publication in the public portal 


\title{
Shear and Foundation Effects on Crack Root Rotation and Mode Mixity in Moment and Force Loaded SCB Sandwich Specimen
}

\author{
Vishnu Saseendran $^{1}$, Leif A. Carlsson ${ }^{2}$ and Christian Berggreen ${ }^{1}$
}

\begin{abstract}
Foundation effects play a crucial role in sandwich fracture specimens with a soft core. Accurate estimation of deformation characteristics at the crack front is vital in understanding compliance, energy-release rate and mode-mixity in fracture test specimens. Beam on elastic foundation analysis of moment and force loaded SCB sandwich fracture specimens is presented here. In addition, finite element analysis of the SCB specimen is conducted to determine displacements, rotations, energy release rate and mode-mixity. Based on finite element analysis, a foundation modulus is proposed that closely agrees with the numerical compliance and energy release rate results for all cases considered. An analytical expression for crack root rotation of the loaded upper face sheet provides consistent results for both loading configurations. For the force loaded SCB specimen (in contrast to the moment loaded case), it was found that the crack length normalized energy release rate and the mode mixity phase angle increase strongly as the crack length decreases, a result of increased dominance of shear loading.
\end{abstract}

${ }^{1}$ Department of Mechanical Engineering, Technical University of Denmark, Denmark ${ }^{2}$ Department of Ocean \& Mechanical Engineering, Florida Atlantic University, USA

\section{Corresponding author:}

Vishnu Saseendran, Department of Mechanical Engineering

Technical University of Denmark, Nils Koppels Allé

Building 404, 2800 Kgs. Lyngby, Denmark

E-mail: vsas@mek.dtu.dk 


\section{Keywords}

Elastic foundation, SCB, root rotation, CSDE, debond, sandwich, DCB-UBM

\section{Introduction}

A serious failure mode of sandwich structures is the separation of face and core. The problem is pertinent to design of such structures not only because this failure mode impairs the strength but also leads to substantial loss of stiffness. A particular characteristic of sandwich structures is that they are "tri-materials" with very large mismatch in elastic properties of the two faces and core. In general, face/core debonds are loaded in mixed mode (combined opening and shear). Since the fracture resistance depends on the mode mixity, a reliable way of assessing the mode mixity is needed. Hence, the mixed-mode face/core sandwich debond problem needs to be addressed in a comprehensive way, both from an analytical and experimental approach. Analysis of face/core crack in sandwich specimens has been

presented by $\varnothing$ stergaard and Sørensen ${ }^{1}$ and Kardomateas et al. ${ }^{2}$. Kardomateas et al. ${ }^{2}$ developed closed-form expressions for the mode mixity of a face/core interface crack in a sandwich element under axial force and moment loading. The sandwich element considered, however is free from transverse shear forces. 
Transverse shear forces are very common part of the loading of most sandwich structures. Transverse shear forces exist in many fracture test specimens such as DCB, ENF, TSD and MMB ${ }^{3-6}$. Lu et al. ${ }^{7}$ considered a homogenous cantilever beam with an embedded delamination under transverse force loading, and generated results for energy release rate using finite element analysis (FEA). Li et al. ${ }^{8}$ examined the influence of shear in beam-like element under axial and transverse forces and bending moments using FEA. As discussed by Li et al. ${ }^{8}$, a vertical section of the upper face layer indicated in Figure 1 will rotate because of foundation effects. The influence of root rotation significantly affect the fracture parameters. As discussed by Timoshenko ${ }^{9}$, Barber ${ }^{10}$ and Li et al. ${ }^{8}$, in general the rotation is not uniform across the section. The transverse shear and rotation must be incorporated in the fracture mechanics analysis. Li et al. ${ }^{8}$ found large influence of transverse shear on the energy release rate and mode-mixity phase angle at short crack lengths.

More recently Andrews and Massabò ${ }^{11}$ proposed a crack element approach where transverse shear forces are acting and developed a superposition scheme. Their approach utilizes the fact that the root rotation depends linearly on crack tip stress resultants, and provide numerically obtained compliance coefficients. In the case of sandwich face/core interface, understanding the crack tip deformation characteristics is vital especially when the analyzed fracture specimen utilizes a soft core. 


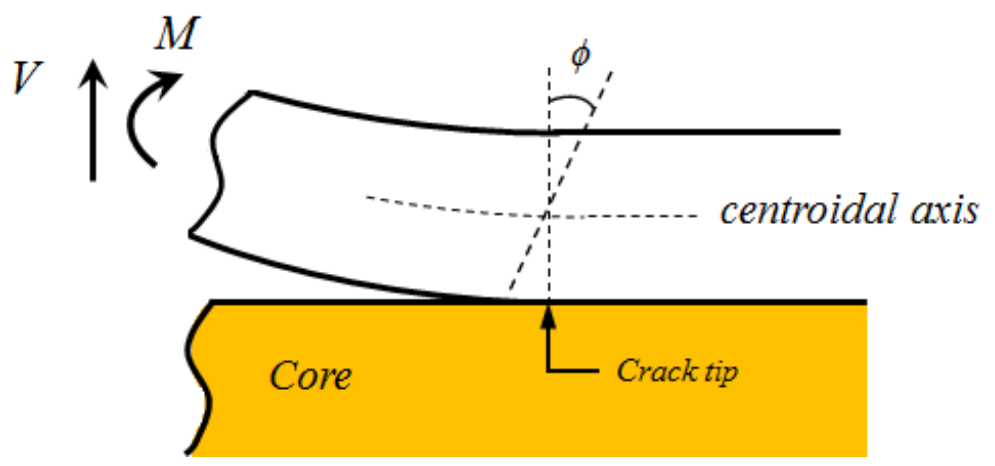

Figure 1. Illustration of crack root rotation.

The main objective of this paper is to examine foundation effects on crack root rotation, energy release rate and mode mixity phase angle for two cases of loading of a Single Cantilever Beam (SCB) sandwich fracture test specimen, i.e. moment and force loadings. The moment loaded SCB specimen is solved using the Winkler elastic foundation model, to obtain the deformation characteristics of the debonded face sheet. A robust analytical framework which captures the influence of the transverse shear force is developed. In addition, the two SCB configurations are analyzed using FEA. Comparisons are made against commonly used expressions for the foundation modulus. 


\section{Sandwich Fracture Specimens}

A sandwich debond specimen, first introduced for testing of monolithic composites by Sørensen et al. ${ }^{12}$ and later extended to sandwich debond testing by Lundsgaard-Larsen et al. ${ }^{13}$ is the DCB-UBM specimen shown in Figure 2a. In this test, edge moments $M_{0}$ and $M_{l}$ are applied until the crack propagates. The right end of the beam is supported to remain horizontal. Moments and rotations of the beams are recorded during the test. The fracture toughness, $G_{c}$, is determined from a critical set of moments required to propagate the crack, using a $J$-integral expression for the energy release rate, $G$.

The force loaded SCB specimen, shown schematically in Figure 2b, was proposed by Cantwell and Davies ${ }^{14}$ to determine face/core fracture toughness. This specimen has received much attention recently ${ }^{15,16}$ and is currently a candidate for ASTM standardization ${ }^{17}$. The entire lower surface of the bottom face sheet is rigidly supported. A vertical load, $P$, acts on the top face sheet where a pre-crack of length, $a$, exists. Load is applied until the crack propagates. Both load and displacement are recorded. Fracture toughness, expressed as the critical energy release rate, $G_{c}$, is then computed from experimental test results using several data reduction schemes ${ }^{16,17}$. 


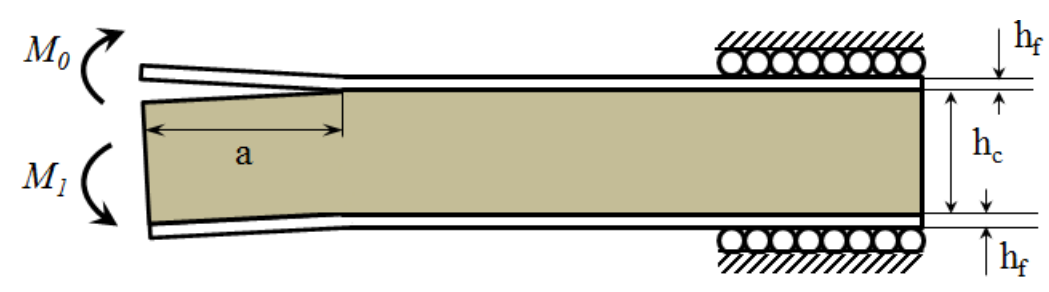

(a)

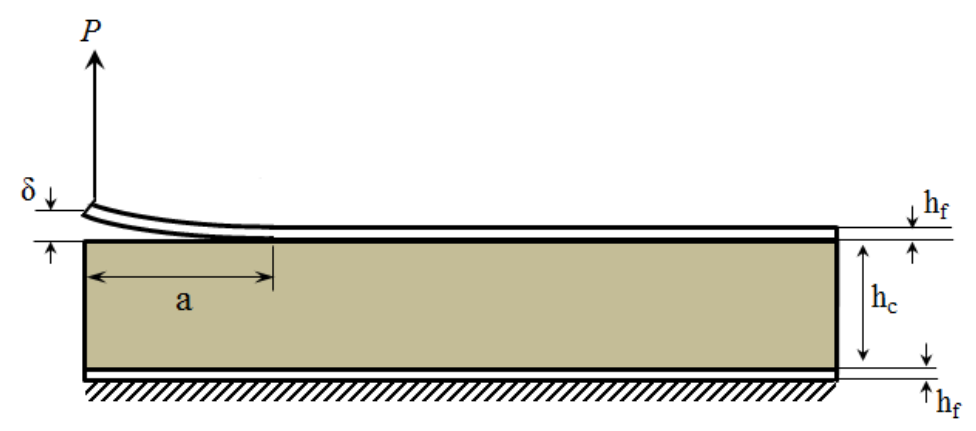

(b)

Figure 2. Face/core debond test specimens. (a) Moment loaded DCB-UBM specimen, (b) Force-loaded SCB specimen. 


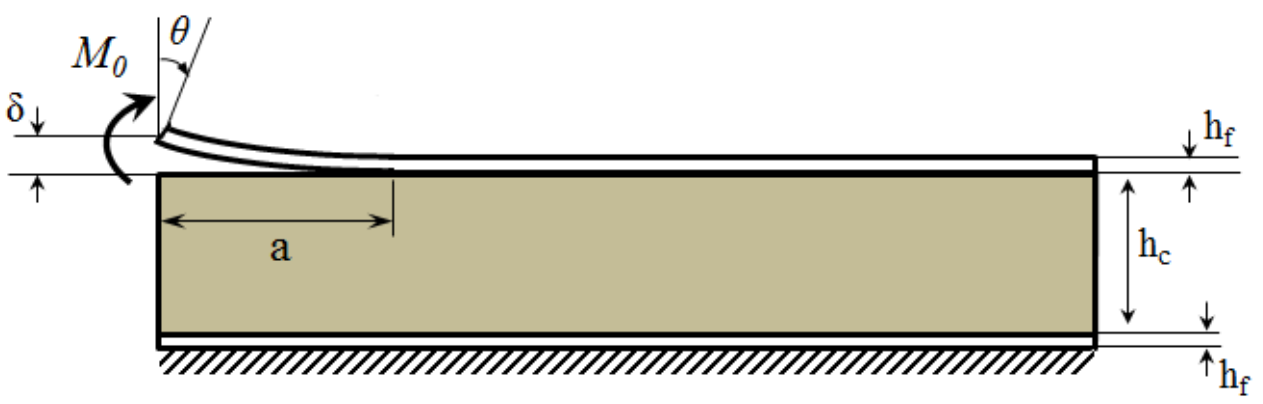

Figure 3. Moment-loaded SCB specimen.

In an effort to examine foundation effects in the moment-loaded DCB-UBM specimen (Figure 2a), a moment-loaded SCB specimen is considered here, see Figure 3. The extension of this analysis to the DCB-UBM specimen will be presented in a related paper. It is recognized that the traditional force loaded SCB specimen, Figure $2 b$, is actually both force and moment loaded, since the transverse force acts at a distance, $a$ from the crack tip, which corresponds to a moment, $M=P a$ at the tip. The moment and shear effects in this specimen configuration will be separated in the current paper.

The deformation characteristics of the debonded face sheet in both force and moment loaded specimens (see Figures 2(a) and 3) are studied using the beam on elastic foundation approach, first suggested by Kanninen ${ }^{18}$. A Winkler foundation is used to approximate the core. The core has also been modeled using higher-order sandwich theories ${ }^{19,20}$. The Winkler foundation approach, however is proven to be adequate ${ }^{3,8,15,21-23}$. 


\section{Moment loaded semi-infinite beam resting on an elastic foundation}

The sandwich DCB-UBM consists of a moment loaded upper face sheet resting on the core bonded to the lower face sheet. Figure 4 shows the foundation model representation of this part of the DCB-UBM specimen, i.e., a SCB sandwich specimen loaded with an edge couple of magnitude $M_{o}$.

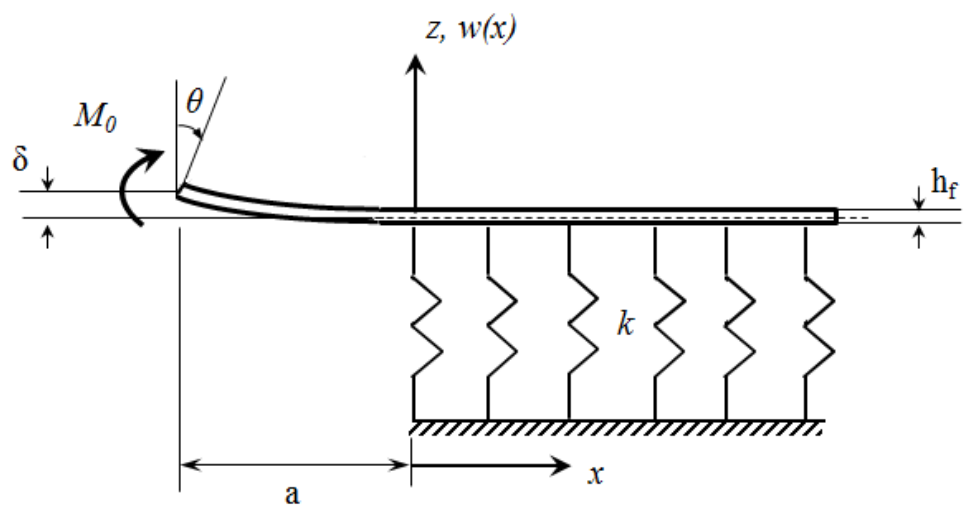

Figure 4. Foundation model of moment loaded SCB specimen.

In order to derive an analytical framework involving crack root rotation for the moment loaded SCB specimen, the deformation kinematics must be determined. The un-cracked region of the top face can be perceived as a beam supported on the core acting as an elastic foundation. The governing equation for the deflection, $w(x)$, of a beam supported by an elastic foundation has been presented by Barber ${ }^{10}$, 


$$
E I \frac{d^{4} w}{d x^{4}}+k H(x) w=0
$$

where

$$
H(x)=\left\{\begin{array}{l}
1, x>0 \\
0, x<0
\end{array}\right.
$$

where $E$ is the Young's modulus of the face sheet, $I$ is the moment of inertia of the face sheet and $k$ is the foundation modulus. The $x$-axis is defined in Figure 4. The general solution to the homogenous Equation (1) can be written as:

$$
w(x)=B_{1} e^{\lambda x} \cos (\lambda \mathrm{x})+B_{2} e^{\lambda x} \sin (\lambda \mathrm{x})+B_{3} e^{-\lambda x} \cos (\lambda \mathrm{x})+B_{4} e^{-\lambda x} \sin (\lambda \mathrm{x})
$$

where

$$
\lambda=\sqrt[4]{\frac{k}{4 E_{f} I}}
$$

In the foundation model representation of the moment loaded SCB specimen, the debonded face sheet is considered as a beam resting on an elastic foundation (see Figure 4). For the case of a semi-infinite beam, the effects from one end will decay before the other end is 
reached. In other words, only the exponentially decaying terms in Equation (2) may be retained. Therefore, the displacement is of the form ${ }^{10}$ :

$$
w(x)=B_{3} e^{-\lambda x} \cos (\lambda \mathrm{x})+B_{4} e^{-\lambda x} \sin (\lambda \mathrm{x})
$$

Progressive derivatives of Equation (4) provide the slope $\theta$, bending moment, $M$ and shear force, $V$ :

$$
\begin{gathered}
\mathrm{w}(x)=B_{3} f_{1}(\lambda \mathrm{x})+\mathrm{B}_{4} f_{2}(\lambda \mathrm{x}) \\
\theta(x)=\frac{d w(x)}{d x}=-B_{3} \lambda f_{3}(\lambda \mathrm{x})+B_{4} \lambda f_{4}(\lambda \mathrm{x}) \\
M(x)=-E I \frac{d w^{2}(x)}{d x^{2}}=-\frac{B_{3} k}{2 \lambda^{2}} f_{2}(\lambda \mathrm{x})+\frac{B_{4} k}{2 \lambda^{2}} f_{1}(\lambda \mathrm{x}) \\
V(x)=\frac{d M(x)}{d x}=-\frac{B_{3} k}{2 \lambda} f_{4}(\lambda \mathrm{x})+\frac{B_{4} k}{2 \lambda} f_{3}(\lambda \mathrm{x})
\end{gathered}
$$

where

$$
\begin{aligned}
& f_{1}(\lambda x)=e^{-\lambda x} \cos (\lambda x) \\
& f_{2}(\lambda x)=e^{-\lambda x} \sin (\lambda x) \\
& f_{3}(\lambda x)=e^{-\lambda x}(\cos (\lambda x)+\sin (\lambda x)) \\
& f_{4}(\lambda x)=e^{-\lambda x}(\cos (\lambda x)-\sin (\lambda x))
\end{aligned}
$$


The parameters $B_{3}$ and $B_{4}$ in Equations (4) can be determined from any two boundary conditions at $x=0$. From Figure 4, the boundary conditions at $x=0$ are: $V=0$ and $M=M_{o}$. Substitution into Equations (4c and 4d) yields:

$$
B_{3}=M_{o} \frac{2 \lambda^{2}}{k} ; B_{4}=-M_{o} \frac{2 \lambda^{2}}{k}
$$

Substituting Equations (6) into (4) gives expressions for displacement, slope, bending moment and shear force for the interval $(0, \infty)$ as:

$$
\begin{gathered}
\mathrm{w}(x)=\frac{M_{o} 2 \lambda^{2}}{k}\left(f_{1}(\lambda \mathrm{x})-f_{2}(\lambda \mathrm{x})\right) \\
\theta(x)=\frac{d w(x)}{d x}=-\frac{M_{o} 2 \lambda^{3}}{k}\left(f_{3}(\lambda \mathrm{x})-f_{4}(\lambda \mathrm{x})\right) \\
M(x)=E I \frac{d w^{2}(x)}{d x^{2}}=-M_{o}\left(f_{2}(\lambda \mathrm{x})-f_{1}(\lambda \mathrm{x})\right) \\
V(x)=E I \frac{d w^{3}(x)}{d x^{3}}=-M_{o} \lambda\left(f_{4}(\lambda \mathrm{x})+f_{3}(\lambda \mathrm{x})\right)
\end{gathered}
$$

The deflection of the debonded face sheet can be obtaining by solving the homogenous Equation (1) for the interval $(-a, 0)$ with $k=0$ : 


$$
E I \frac{d^{4} w}{d x^{4}}=0
$$

The general solution is of the form:

$$
w(x)=C_{1} \frac{x^{3}}{6}+C_{2} \frac{x^{2}}{2}+C_{3} x+C_{4}
$$

The constants $C_{1}$ and $C_{2}$ are obtained by utilizing the boundary conditions $V(x=0)=0$ and $M(x=0)=M_{o}$. Furthermore, the deflection, slope and shear force at the top face sheet must be continuous. Such conditions mandate that deflection in the two intervals $(-a, 0)$ and $(0$, $\infty)$, and the three progressive derivatives must match at $x=0$. Invoking continuity yields,

$$
C_{1}=0 ; C_{2}=\frac{M_{o}}{E I} ; C_{3}=-\frac{4 M_{o} \lambda^{3}}{k} ; C_{4}=\frac{2 M_{o} \lambda^{2}}{k} \quad(10 \mathrm{a}, \mathrm{b}, \mathrm{c}, \mathrm{d})
$$

Substituting the constants from Equations (10) into (9) provides the deflection of the top face sheet in the interval $(-a, 0)$ as:

$$
\mathrm{w}(x)=M_{o}\left[\frac{x^{2}}{2 E I}-\frac{4 \lambda^{3} x}{k}+\frac{2 \lambda^{2}}{k}\right] ; \quad-a \leq x \leq 0
$$

Therefore, the deflection, $w(x)$ and rotation, $\theta(x)$ of the moment loaded beam are given by: 


$$
\begin{gathered}
w(x)=M_{o} \begin{cases}\frac{x^{2}}{2 E I}-\frac{4 \lambda^{3} x}{k}+\frac{2 \lambda^{2}}{k} & (-a \leq x \leq 0) \\
\frac{2 \lambda^{2}}{k}\left[f_{1}(\lambda x)-f_{2}(\lambda x)\right] & (0 \leq x \leq \infty)\end{cases} \\
\theta(x)=\frac{d w}{d x}=M_{o} \begin{cases}\frac{x}{E I}-\frac{4 \lambda^{3}}{k} & (-a \leq x \leq 0) \\
\frac{2 \lambda^{2}}{k}\left[-f_{3}(\lambda \mathrm{x})-f_{4}(\lambda \mathrm{x})\right] & (0 \leq x \leq \infty)\end{cases}
\end{gathered}
$$

where the functions $f_{1}, f_{2}, f_{3}$ and $f_{4}$ are provided in Equation (5) and the parameter $\lambda$ is defined in Equation (3). The compliance of the moment loaded SCB specimen can be defined as the edge rotation divided by the applied moment, i.e.

$$
C=\frac{|\theta(-a)|}{M_{0}}
$$

Equation (12a) gives,

$$
C=\frac{a}{E I}+\frac{4 \lambda^{3}}{k}
$$

Now, the energy release rate is of the form:

$$
G=\frac{M^{2}}{2 b} \frac{d C}{d a}
$$


where $C$ is given in Equation (14b). Upon substitution, the energy release rate of the moment loaded SCB specimen becomes,

$$
G=\frac{M_{o}^{2}}{2 b E I}
$$

Equation (16) shows that the energy release rate for the moment loaded SCB specimen is independent of the crack length and foundation modulus, $k$. It should be noted that the deflection and rotation of beam with a built-in end at $x=0$, can be recovered from Equations (12) and (13) by letting $k \rightarrow \infty$. For this case,

$$
\begin{array}{r}
w(-\mathrm{a})=M_{0} a^{2} / 2 E I \\
\theta(-\mathrm{a})=-M_{0} / 2 E I
\end{array}
$$

The definition of elastic foundation modulus, $k$ (see Equation 1), is not straight-forward. Kanninen ${ }^{18}$ considered a symmetric homogenous isotropic DCB specimen of total thickness, $h$, and assumed that each half of the specimen will deform and act as a foundation. Li and Carlsson ${ }^{21}$ proposed an expression for the foundation modulus of a SCB sandwich specimen by assuming the full height of the core acts as a foundation. Avilés and Carlsson ${ }^{3}$ analysed an un-symmetric DCB sandwich specimen loaded with two forces and assumed that half of 
the core height acts as a foundation. Quispitupa et al. ${ }^{24}$ proposed a foundation modulus for a MMB sandwich specimen where a region of the core equal to $1 / 2$ of the height of the upper face layer acts as a foundation. The various foundation modulus expressions, $k$, are listed in Table 1 . Note that, in the foundation modulus expression by Kanninen ${ }^{18}, E$ is the Young's modulus of the isotropic beam material. For all cases, and $b$ is the width of the specimen.

Table 1. Elastic foundation modulus, k, proposed in various studies.

\begin{tabular}{|c|c|}
\hline Elastic Foundation Modulus & \\
\hline Kanninen $^{18}$ & $k=\frac{E b}{h / 2}$ \\
\hline Li and Carlsson $^{21}$ & $k=\frac{E_{c} b}{h_{c}}$ \\
\hline Avilés and Carlsson $^{3}$ & $k=\frac{E_{c} b}{h_{c} / 2}$ \\
\hline Quispitupa et al. $^{24}$ & $k=\frac{E_{c} b}{h_{f} / 2}$ \\
\hline
\end{tabular}

\section{Finite Element Analysis of SCB sandwich specimens}

In this section, we will present a detailed numerical finite element analysis (FEA) of both moment and force loaded SCB specimens. The force loaded SCB specimen, Figure 1b, has been examined by several researchers ${ }^{5,15,16,21}$. A brief overview of the governing equations for deflection, compliance and energy-release rate is provided in Appendix A. In addition, 
the mode mixity phase angle is determined from FEA. The results from the FEA will be compared with corresponding results from the foundation model. A symmetrical sandwich with aluminum face sheets $\left(E_{f}=68.9 \mathrm{GPa}, h_{f}=6.35 \mathrm{~mm}\right)$ and a PVC H100 foam core $\left(E_{c}=\right.$ $130 \mathrm{MPa}, h_{c}=25.4 \mathrm{~mm}$ ) is considered. Total length of specimen is, $L=305 \mathrm{~mm}$ and the crack length was varied in the range: $a=1-50 \mathrm{~mm}$. This range of crack lengths should not lead to end effects in the $305 \mathrm{~mm}$ long specimen.

The 2D plane stress finite element model of the SCB specimen is constructed in ANSYS® ${ }^{25}$ with 4-node parabolic elements at the crack tip region with a minimum edge length of 2 $\mu \mathrm{m}$. 8-node parabolic elements were also used in rest of the model but with varying sizes. Figure 5 shows the finite-element model with a detailed view of the highly refined mesh near the crack tip. The energy release rate and mode mixity phase angle are obtained from a method called Crack Surface Displacement Extrapolation (CSDE) method ${ }^{26}$ implemented in the FEA. A brief description of CSDE method is provided in Appendix B. Mode-mixity is expressed in terms of phase angle $(\psi)$ which is roughly the ratio between sliding shear and normal opening displacements of the crack flanks. A "reduced" formulation of phase angle $(\psi)$ is used here so that mode-mixity can be defined similar to that for homogenous materials

27. This formulation circumvents the oscillation of displacements in the near tip region. 


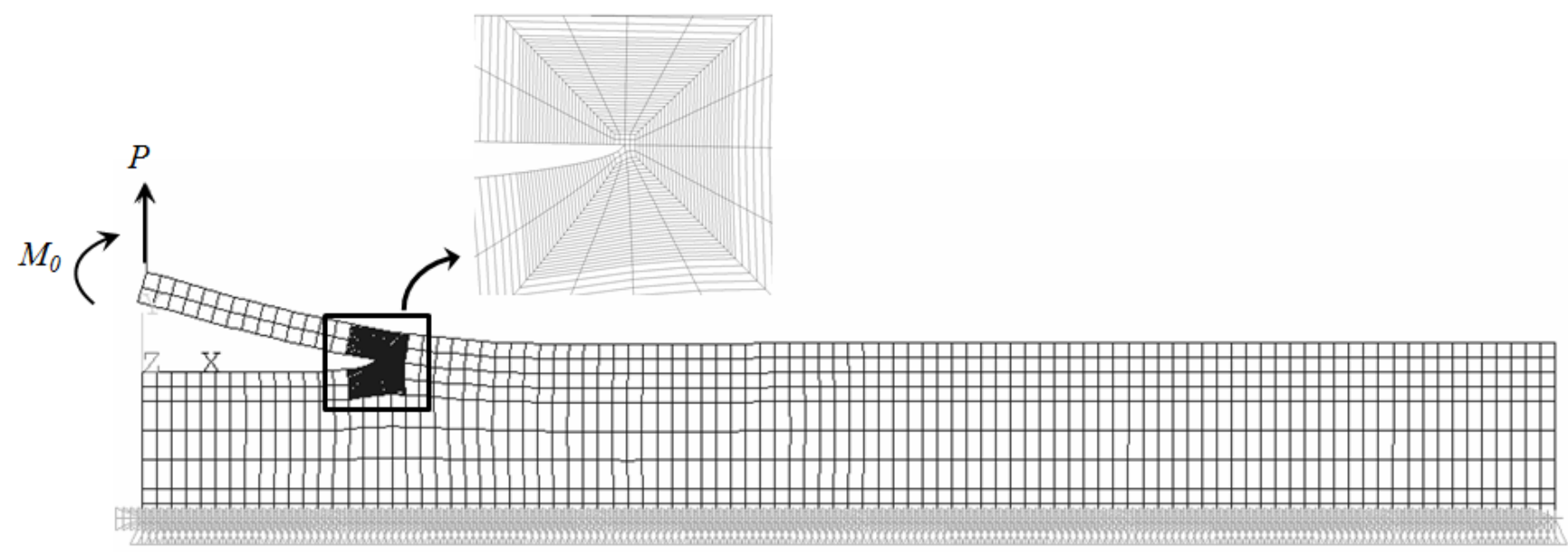

Figure 5. FE-model of a SCB sandwich specimen end-loaded with force, $\mathrm{P}$ or moment, $\mathrm{M}$. Smallest element edge length $=2 \mu \mathrm{m}$.

\section{Moment loaded SCB results}

A moment $M_{o}=1 \mathrm{~N} \cdot \mathrm{mm} / \mathrm{mm}$ is applied to edge of the upper face sheet of the SCB specimen (with $P=0$, see Figure 5). The moment was applied to a master node at the left edge of the face sheet. Displacement, $\delta$, and rotation, $\theta$, (Figure 5) are recorded for the range of crack lengths considered.

The numerically and analytically obtained end displacement and rotation are shown vs. crack length in Figure 6. Results are shown for the various foundation modulus estimates listed in Table 1. It is noted that the displacement increases with increasing crack length and reduced 
foundation modulus. The rotation (Figure $6 \mathrm{~b}$ ) varies linearly with crack length. A foundation modulus expression proposed here, provides a close match with the FEA results.

$$
k=\frac{E_{c} b}{h_{c} / 4}
$$

Notice that this expression corresponds to $1 / 4$ of the core thickness being active as a foundation. 

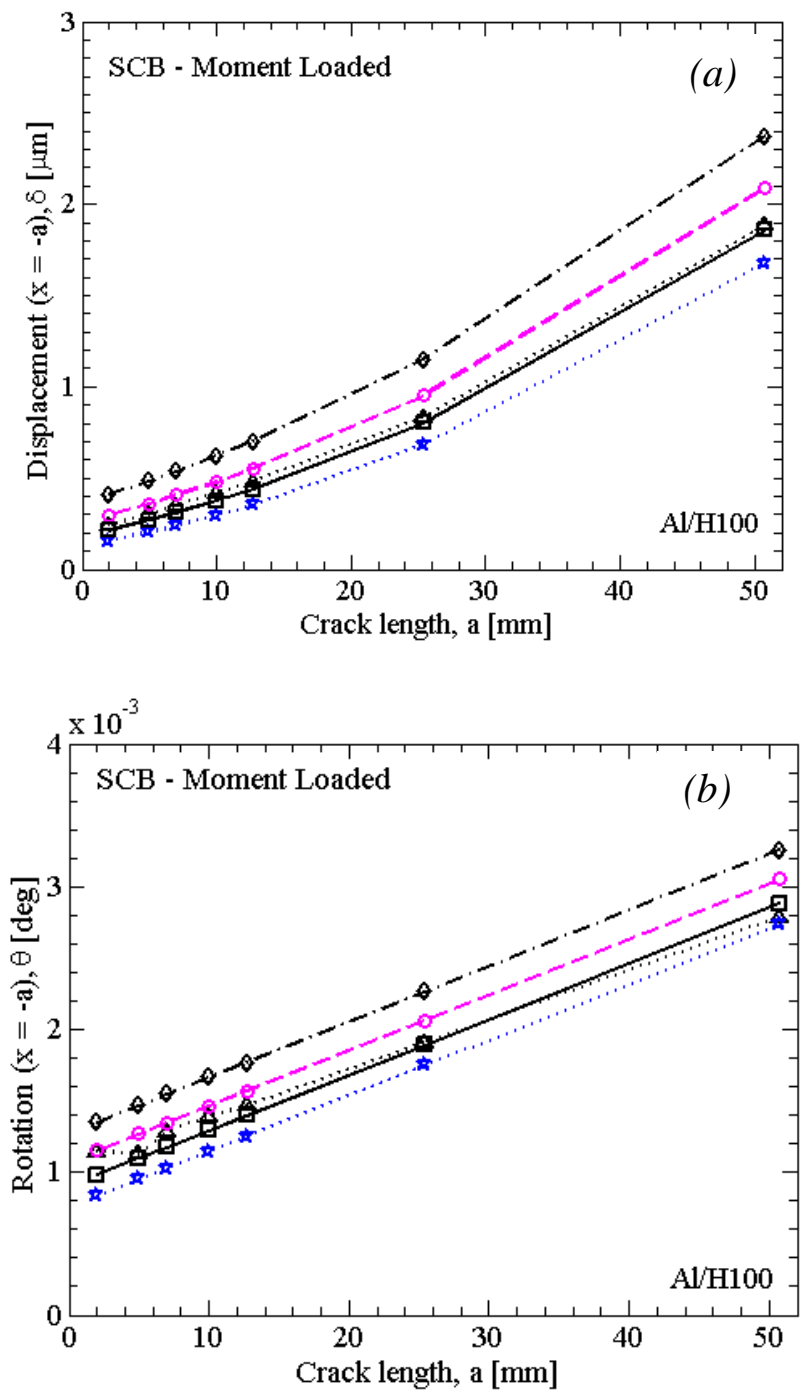
Figure 6. Deflection (a) and rotation (b) at the edge of the upper face layer $(x=-a)$ of moment-loaded SCB specimen (A1/H100) $(\mathrm{M}=1 \mathrm{~N}) . \cdots \Delta \cdots \mathrm{FEA}-\ominus-k=E_{c} b /\left(h_{c} / 2\right)$ $\cdots \cdots \cdot k=E_{c} b /\left(h_{f} / 2\right)-\diamond \cdots k=E_{c} b / h_{c} \rightarrow-k=E_{c} b /\left(h_{c} / 4\right)$ (Eq. 18).

A plot of energy-release rate $G$, normalized by $E_{f} h_{f}^{3}$ against crack length is provided in Figure 7. $G$ determined from FEA is relatively unaffected by crack length, which is consistent with the analytical foundation model expression for $G$, Equation (16). The results are in very good agreement. A difference of $3 \%$ is observed between the FEA and analytical expression for all the range of crack lengths considered here. 


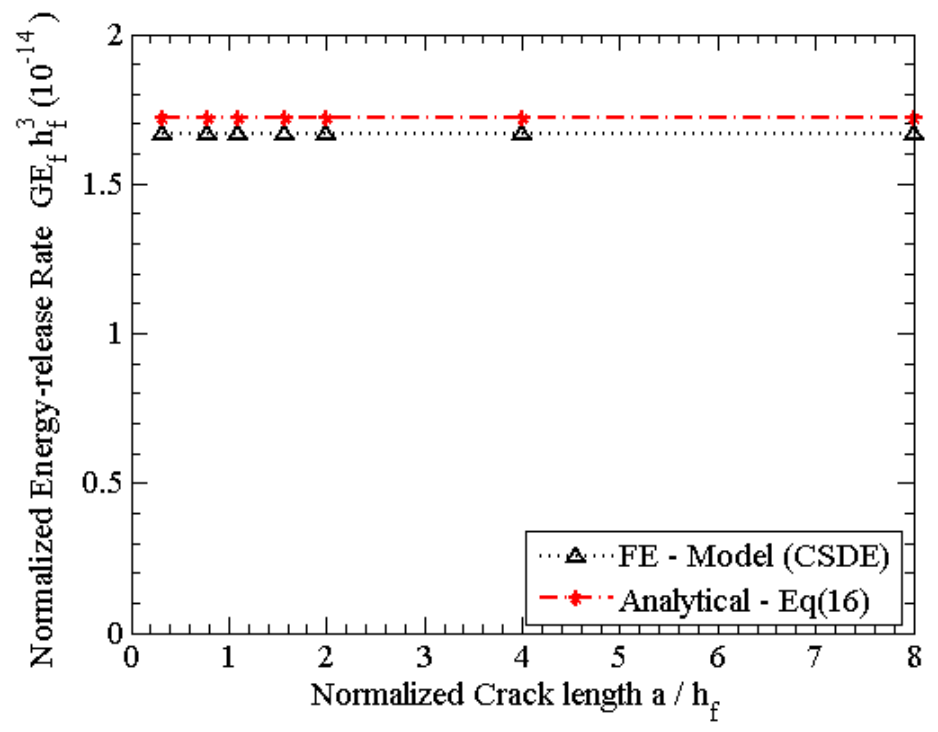

Figure 7. Energy-release rate (normalized) vs. crack length for moment loaded Al/H100 SCB sandwich specimen calculated from FEA and analytical expression (Equation 16).

\section{Force loaded $S C B$ results}

For the force loading, a single unit force $(P=1 \mathrm{~N})$ was applied to the edge of the upper face layer in the SCB sandwich specimen, Figure $5\left(M_{o}=0\right)$. The compliance, $C$, is defined as the displacement, $\delta$, of the load application point divided by the applied force, $P$. The analytical compliance is obtained from Equation (A2).

Figure 8 shows a plot of compliance vs. crack length for a force loaded SCB sandwich specimen determined from FEA and the foundation model, Equation (A3) with the various 
foundation modulus expressions listed in Table 1. The compliance increases with increasing crack length and decreasing foundation modulus. The newly proposed foundation modulus expression, Equation (18), provides a compliance that closely agrees with the numerically obtained results.

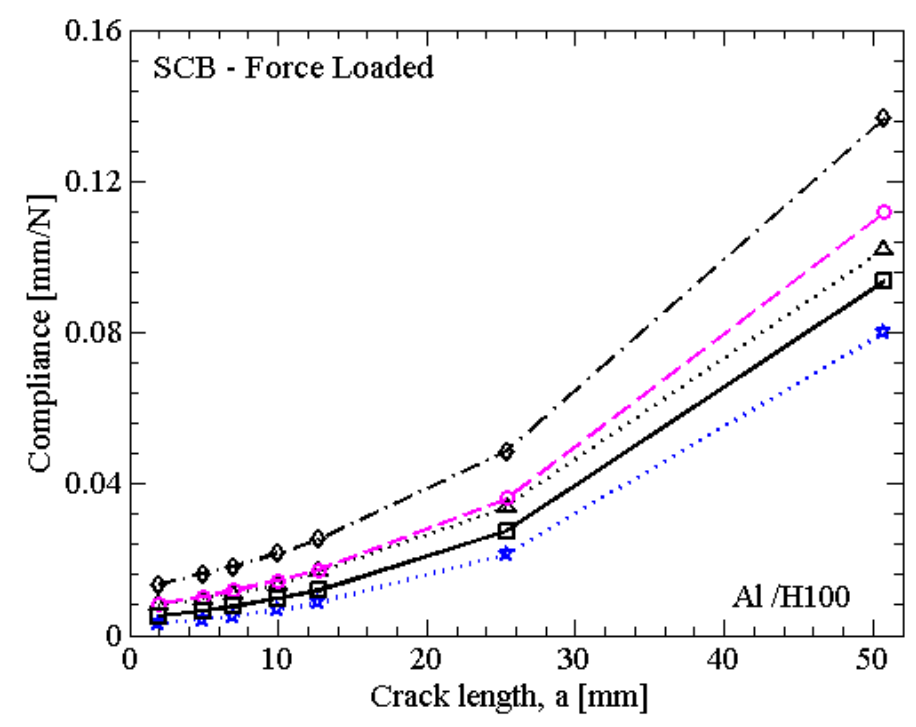

Figure 8. Compliance vs crack length for force loaded Al/H100 SCB sandwich specimen;

$$
\begin{aligned}
& \left(\mathrm{h}_{\mathrm{f}}=6.35 \mathrm{~mm}, \mathrm{~h}_{\mathrm{c}}=25.4 \mathrm{~mm}\right), \mathrm{P}=1 \mathrm{~N} / \mathrm{mm} . \cdots \Delta \cdots F E A-k=E_{c} b /\left(h_{c} / 2\right) \\
& \cdots \cdots k=E_{c} b /\left(h_{f} / 2\right)-\vartheta k=E_{c} b / h_{c} \rightarrow-k=E_{c} b /\left(h_{c} / 4\right) \text { (Eq. 18). }
\end{aligned}
$$

A plot of $G$ normalized by $E_{f} h_{f}^{3} / a^{2}$ vs. crack length is provided in Figure 9. G was also calculated based on Equation (A7) for the various foundation modulus expressions provided 
in Table 1. It is noted that $\mathrm{G}$ normalized in this manner increases sharply for short crack lengths. This trend is similar to what was observed by Li et al. ${ }^{8}$ for their single shear force case. It can be noted that $G$ computed using the proposed foundation modulus expression (Equation 18) closely agrees with the numerically obtained $G$.

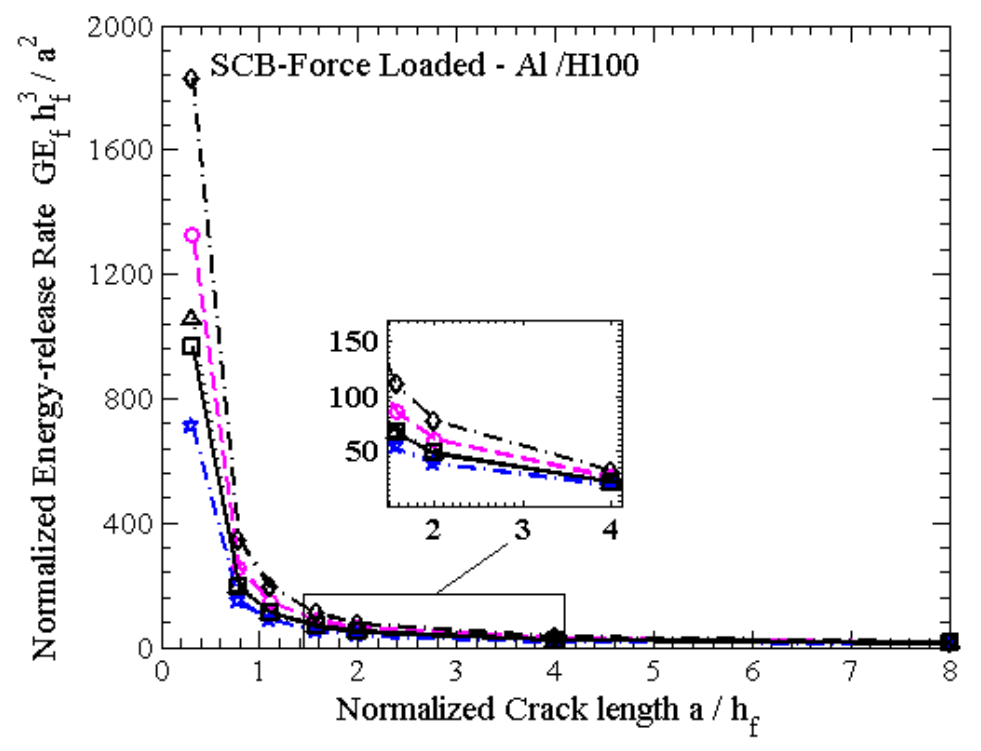

Figure 9. Energy-release rate (normalized) vs. crack length for force loaded Al/H100 SCB sandwich specimen calculated from FEA and foundation model. $\cdots \Delta \cdot \cdots$ FEA

$$
\begin{gathered}
-k=E_{c} b /\left(h_{c} / 2\right) \cdots \cdots k=E_{c} b /\left(h_{f} / 2\right)-\bullet \cdot k=E_{c} b / h_{c} \\
\square-k=E_{c} b /\left(h_{c} / 4\right) \text { (Eq. 18). }
\end{gathered}
$$




\section{Crack tip root rotation}

There exist several methods in the literature to estimate root rotation in a bi-material interface. Sun and Pandey ${ }^{28,29}$ estimated root rotation based on an approximate analytical method. Wang and Qiao $^{30}$ determined root rotation from a closed form displacement solution, obtained for two beams by utilizing a modified first-order shear deformable plate theory. Andrews and Massabò ${ }^{11}$ obtained root rotation for an orthotropic beam using the finite

element method. In the work presented by Andrews and Massabo ${ }^{11}$. Their analysis of near tip deformation characteristics was extended to orthotropic bi-material interface using a first order shear deformation theory. Li et al. ${ }^{8}$ proposed a dimensionless expression for the crack root rotation as a function of axial force, shear force and bending moment as well as elastic constants and geometry of the face sheet which is followed here applied to both force and moment loaded SCB sandwich specimen.

As discussed earlier, a section just behind the crack tip initially normal to the centroidal axis of the face sheet will rotate upon loading of the face sheet by application of shear force, $V$ and moment, $M$, see Figure 1 . The root rotation is defined by:

$$
\phi=\frac{\partial u_{x}}{\partial z}
$$


where $u_{x}$ is the $x$-component of the displacement of the initially straight normal to the cross section. Based on the foundation analysis here, the kinematics of the upper face sheet is assumed to follow Euler-Bernoulli beam theory, and the rotation angle is found by differentiating the equation for the deflection to obtain the slope, $d w / d x$ at $x=0$. For the moment loaded SCB specimen, the crack root rotation angle is directly obtained from Equation (13) as:

$$
\phi_{\text {Moment }}=-\frac{4 M_{0} \lambda^{3}}{k}
$$

For the force loaded SCB specimen, Equation (A1) yields,

$$
\phi_{\text {Force }}=\frac{-2 \lambda^{2}}{k} P(1+2 a \lambda)
$$

By considering a crack that is long enough the avoid boundary effects, Li et al. ${ }^{8}$ suggest that the root rotation angle can be expressed as:

$$
\phi_{A}=c_{M} \frac{M}{\bar{E}_{f} h_{f}^{2}}+c_{N} \frac{N}{\bar{E}_{f} h_{f}}+c_{V} \frac{V}{\bar{E}_{f} h_{f}}
$$

where the coefficients $c_{M}, c_{P}$ and $c_{V}$ depend on the face and core stiffnesses. $M$ is the moment, $N$ the axial load and $V$, the shear force in the upper face (all per unit width) at the crack tip 
where $E_{f}$ and $v_{\mathrm{f}}$ are Young's modulus and Poisson's ratio of face sheet. For plane strain condition, $\bar{E}_{f}=E_{f} /\left(1-v_{f}^{2}\right)$ and for plane stress condition, $\bar{E}_{f}=E_{f}$.

Figure 10 shows the root rotation angle $(\phi)$ vs. foundation modulus, $k$, for the moment loaded SCB specimen determined from Eq. (20) at a crack length, $a=2 \mathrm{~mm}$, and the angle determined by FEA. The rotation angle is quite sensitive to the foundation modulus, $k$. The foundation modulus expression, Equation (18), (see vertical dotted line), provides close agreement with $\phi$ obtained from FEA as marked by the horizontal dotted line the plot.

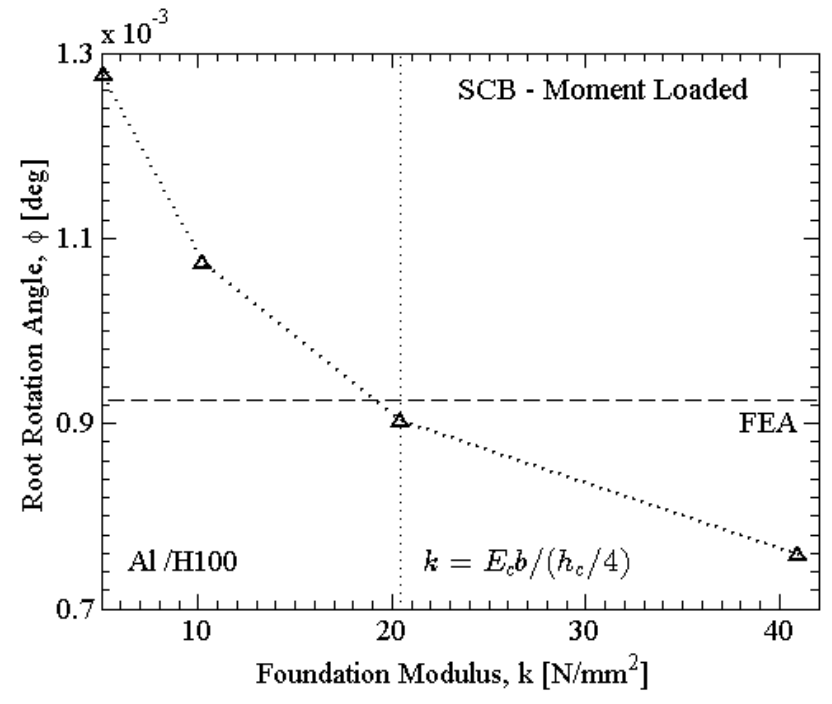

Figure 10. Crack root rotation angle $(\phi)$ vs. foundation modulus, $k$ of a moment loaded SCB specimen, $M_{0}=1 \mathrm{~N}$. 
For force loading, $V=P, M=P a$ and $N=0$. A load, $P=1 \mathrm{~N} / \mathrm{mm}$ was applied. Root rotation angles calculated for two crack lengths, $a=12.7$ and $25.4 \mathrm{~mm}$, were used to determine the coefficients $c_{M}$ and $c_{V}$ from Equation (24): $c_{V}=6.093 \times 10^{3}$ and $c_{M}=2.637 \times 10^{3}$. The coefficients are then used to compute rotation angle for full range of crack lengths using Equation (22). Results are presented in Figure 11. The FEA results agree very well with $\phi_{A}$ obtained from Equation (22) with $c_{M}$ and $c_{V}$ values above, lending confidence to the Li et al. ${ }^{8}$ formulation. Further examination of the force loaded SCB specimens reveal that shear dominates the crack root rotation for crack lengths less than about $15 \mathrm{~mm}$. To further examine the generality Equations (18) and (22) would require analysis of SCB specimens with a wide range of face and core materials and face thicknesses. 


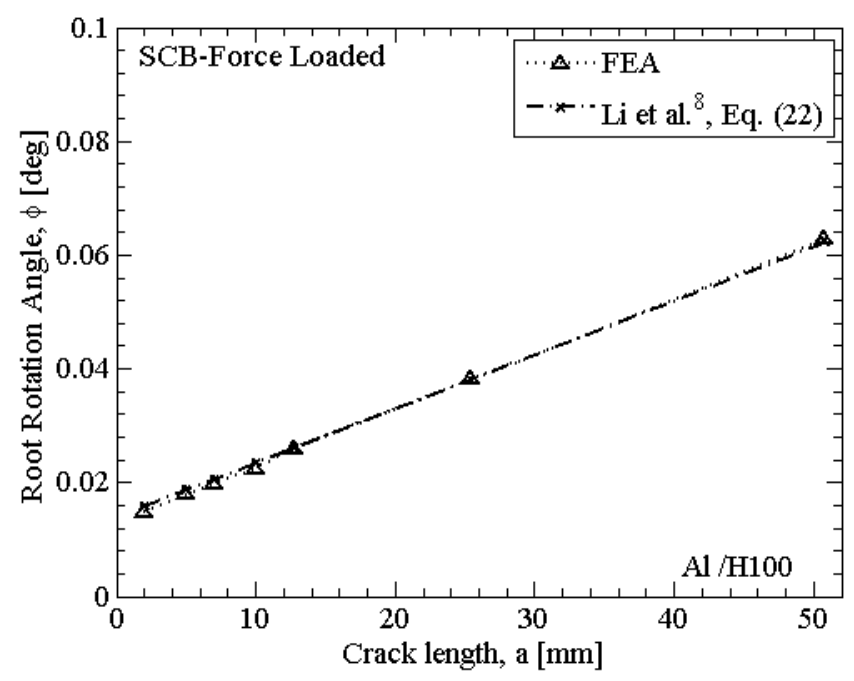

Figure 11. Crack root rotation angle $(\phi)$ for force loaded SCB sandwich specimen

$$
(P=1 \mathrm{~N} / \mathrm{mm}) \text {. }
$$

Now, for the moment loaded SCB specimen, Equation (22) reduces to:

$$
\phi_{A}=c_{M} \frac{M_{0}}{\bar{E}_{f} h_{f}^{2}}
$$

It should be noted that for a moment loaded SCB specimen, $\phi$ does not depend on crack length. The coefficient $c_{M}$ was obtained previously from analysis of the force loaded $\mathrm{Al} / \mathrm{H} 100$ SCB specimen as $c_{M}=2640$. Substituting the value of $c_{M}$ into Equation (23), gives the root rotation angle for an $\mathrm{Al} / \mathrm{H} 100 \mathrm{DCB}$ specimen subject to a moment, $M_{0}=1 \mathrm{~N}$ as: 
$\phi=0.000952^{\circ}$. The root rotation is also obtained from FEA for $M_{0}=1 \mathrm{~N}$, which gives $\phi=0.00093^{\circ}$.

\section{Influence of shear on phase angle $(\psi)$}

The energy-release rate and the complex stress intensity factor for a general bi-material interface was first introduced by Suo and Hutchinson ${ }^{31}$, under the ambit of Linear Elastic Fracture Mechanics (LEFM). The expressions for mode-mixity and energy-release rate

provided in ${ }^{31}$ assume that shear forces are absent. However, the presence of shear force at the crack tip introduces an additional component to the energy-release rate, which in-turn is affected by the crack tip deformation characteristics ${ }^{8,11,30,32,33}$. Li et al. ${ }^{8}$ introduced shear into the energy-release rate and stress intensity factors expressions for isotropic bi-material interfaces, which was later extended by Andrews and Massabò ${ }^{11}$ to orthotropic interfaces.

The force loaded SCB sandwich specimen includes a shear force at the crack tip, in addition to the bending moment. For reliable fracture toughness assessment, the transverse shear component must be incorporated to the energy-release rate calculation. However, closed form expressions for both energy-release rate and the mode-mixity have not yet been derived for a SCB sandwich specimen. In this section, the influence of transverse shear in a SCB specimen is investigated using the numerical mode-mixity method, CSDE. The crack tip 
mode-mixity expressed as phase angle, $\psi$, is estimated using the FEA in conjunction with the CSDE method ${ }^{26,27}$, which is presented briefly in Appendix B.

The force loaded Al/H100 SCB specimen $\left(h_{f}=6.35 \mathrm{~mm}, h_{c}=25.4 \mathrm{~mm}\right)$ subject to a load, $P$ $=1 \mathrm{~N} / \mathrm{mm}$ is analyzed using FEA for over a range of crack lengths from 2 to $50 \mathrm{~mm}$. A plot of phase angle $(\psi)$ against normalized crack length $\left(a / h_{f}\right)$ is shown in Figure 12. It is observed that $\psi$ increases when the crack gets shorter, which is attributed to increased dominance of shear loading at short crack length. The results qualitatively agree with the results from Li et al. ${ }^{8}$ although they analyzed different material combinations. Note that, the phase angle for a pure moment loading $(V=0)$ is, $\psi=4.4^{\circ}$. A plot of the normalized shear load, $V / M$ vs. crack length is also included in Figure 12. The phase angle vs. crack length follows a similar trend as that of the normalized shear load. The phase angle for a moment loaded SCB specimen seems consistent with the trend of $\psi$ as $V / \mathrm{M} \rightarrow 0$. 


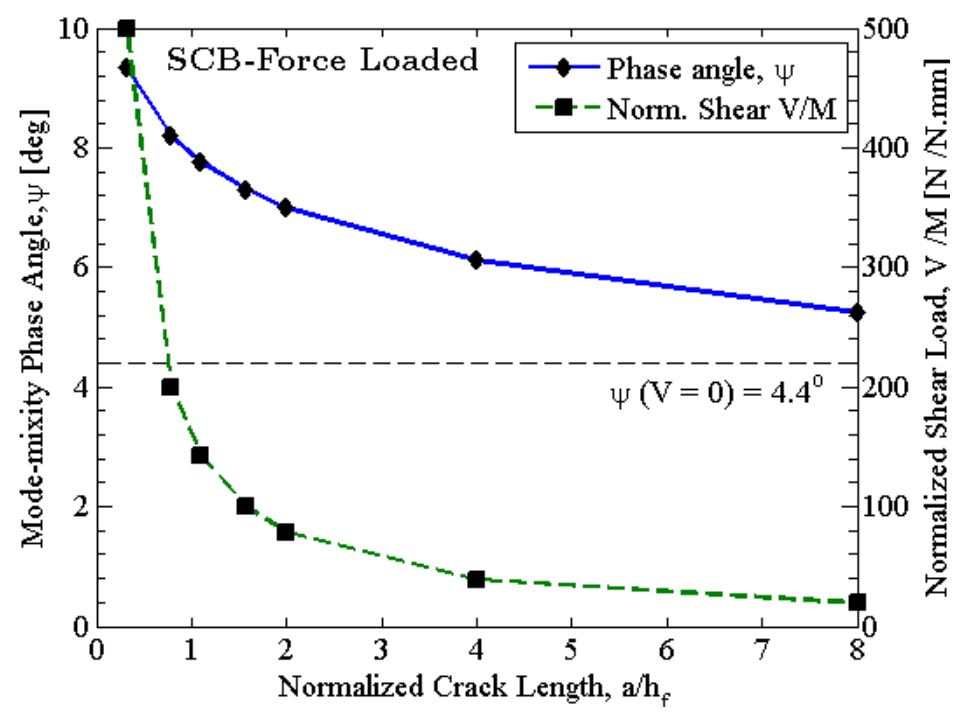

Figure 12. Mode-mixity phase angle $(\psi)$ and normalized shear force vs. crack length for force loaded SCB (Al/H100) specimen.

\section{Conclusions}

Analysis of the SCB sandwich specimen under moment and force loading conditions was presented. The analysis of the moment loaded SCB specimen was conducted using a Winkler beam on elastic foundation approach. The compliance and energy release rate results for both sandwich specimens obtained from foundation model analysis were compared to detailed finite element results. A foundation modulus where $1 / 4$ of the core thickness is utilized as a foundation was seen to agree well with numerically obtained results for both force and 
moment loaded SCB specimens. A closed form expression for crack root rotation was calibrated using FEA results and produced consistent results for both types of loading of the SCB specimen. For the force loaded SCB specimen at short crack lengths, the increased dominance of the shear component was reflected on increased energy release rate and mode mixity phase angle. For the moment loaded SCB specimen, the energy release rate is independent of both crack length and foundation modulus, in contrast to the force loaded SCB specimen. Deformation characteristics at the crack front was accurately estimated using beam on elastic foundation model for both the force and moment loaded SCB configuration. Therefore, the current analysis aids in understanding compliance, energy-release rate and mode-mixity of moment loaded fracture test specimens such as the DCB-UBM specimen.

\section{Appendix A: Foundation analysis of force loaded SCB sandwich specimen}

Foundation analysis of the force loaded SCB sandwich specimen, Figure A1, has been presented by Li and Carlsson ${ }^{21}$. They extended the Kanninen ${ }^{18}$ beam on elastic foundation model for a homogenous Double Cantilever Beam (DCB) specimen to a sandwich specimens with a single transverse force applied to the upper face sheet. The elastic foundation analysis

${ }^{21}$ of the single force loaded SCB sandwich specimen will be briefly reviewed here. 
Figure A1 shows the foundation model and coordinate system for the force loaded SCB sandwich specimen. For simplicity, the analysis will assume that the end effects can be ignored, i.e. it applies to specimens where the un-cracked length is sufficiently long.

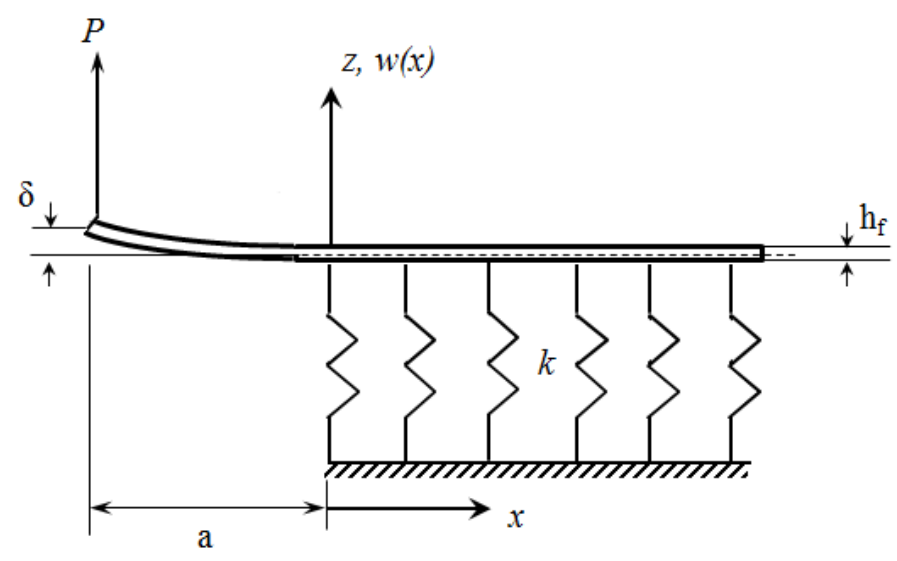

Figure A1. Foundation model of force loaded SCB sandwich specimen.

The displacement solution for the top face sheet is obtained using the governing equation for the beam supported by a Winkler foundation ${ }^{10}$ (see Figure A1). Deflection of the face sheet for a force loaded SCB sandwich specimen is of the form: 


$$
w(x)=\frac{2 P \lambda}{k}\left\{\begin{array}{lr}
\frac{\lambda^{3} x^{3}}{3}+a \lambda^{3} x^{2}-2 a \lambda^{2} x-\lambda(x-a)+1 & (-a \leq x \leq 0) \\
a \lambda \sin (\lambda x) \sinh (\lambda x)-a \lambda \sin (\lambda x) \cosh (\lambda x)+ & (0 \leq x \leq \infty) \\
(a \lambda+1) \cos (\lambda x) \cosh (\lambda x)-(a \lambda+1) \cos (\lambda x) \sinh (\lambda x) & \text { (A1) }
\end{array}\right.
$$

where, $k$ is the foundation modulus, see Equation (3). Impetus is made here to mention that the analysis is carried out using Euler-Bernoulli beam theory. Hence deformation of the beam due to transverse shear is neglected. The bending compliance, $C$ of the force loaded SCB sandwich specimen is given by:

$$
C=\frac{\delta(x=-a)}{P}=\frac{4 \lambda}{k}\left[\frac{\lambda^{3} a^{3}}{3}+\lambda^{2} a^{2}+\lambda a+\frac{1}{2}\right]
$$

The energy release rate is given by ${ }^{34}$ :

$$
G=\frac{2 P^{2} \lambda^{2}}{b k}\left[\lambda^{2} a^{2}+2 \lambda a+1\right]
$$

For a sandwich specimen with infinitely stiff core $(k \rightarrow \infty)$, the compliance and energyrelease rate become,

$$
w(-a)=\frac{P a^{3}}{3 E_{f} I}, G=\frac{P^{2} a^{2}}{2 b E_{f} I}
$$




\section{Appendix B: Numerical mode-mixity method: CSDE}

Crack Surface Displacement Extrapolation (CSDE) method is a numerical mode-mixity method which utilizes a zone near the crack tip. The mode mixity expressed as phase angle $(\psi)$ is a measure of the relative amount of shear and opening at the crack tip ${ }^{26}$ :

$$
\psi=\tan ^{-1}\left(\frac{\delta_{x}}{\delta_{y}}\right)-\varepsilon \ln \left(\frac{x}{h}\right)+\tan ^{-1}(2 \varepsilon)
$$

where $\delta_{x}$ and $\delta_{y}$ are sliding and opening displacements respectively. The parameter, $\varepsilon$ is the oscillatory index defined as ${ }^{27}$ :

$$
\varepsilon=\frac{1}{2 \pi} \ln \left(\frac{1-\beta}{1+\beta}\right)
$$

$\beta$ is a bimaterial interface parameter given by ${ }^{27}$ :

$$
\beta=\frac{G_{1}\left(\kappa_{2}-1\right)-G_{2}\left(\kappa_{1}-1\right)}{G_{1}\left(\kappa_{2}+1\right)+G_{2}\left(\kappa_{1}+1\right)}
$$

where $G_{m}$ is the shear modulus, $m=1$ for the face and, $m=2$ for the core, $\kappa_{m}=3-4 v_{m}$ for plane strain and $\kappa_{m}=\left(3-4 v_{m}\right) /\left(1+v_{m}\right)$ for plane stress. $v_{m}$ is Poisson's ratio. 
Non-zero $\varepsilon$ and $\beta$, imply that stresses and displacements in the near tip region oscillate leading to interpenetration of crack faces which is physically impossible. This phenomenon may be downplayed by assuming $\beta=0{ }^{35}$. This approach with $\varepsilon=\beta=0$ is denoted as "reduced formulation". The phase angle $(\psi)$ becomes:

$$
\psi=\tan ^{-1}\left(\frac{\delta_{x}}{\delta_{y}}\right)
$$

The energy release rate can be computed from the crack flank displacement:

$$
G=\frac{\pi\left(\delta_{x}^{2}+\delta_{y}^{2}\right)}{2 x\left(\mathrm{c}_{1}+\mathrm{c}_{2}\right)}
$$

where $x$ is the distance from the crack tip and the stiffness parameters, $c_{1}$ and $c_{2}$ are given by:

$$
c_{m}=\frac{\kappa_{m}+1}{G_{m}}
$$

where $G_{m}$ is the shear modulus, ( $m=1$ and 2 for face and core). The CSDE method is implemented as a subroutine in ANSYS ${ }^{\circledR}{ }^{25}$. 


\section{Acknowledgements}

The financial support from the Danish Centre for Composite Structures and Materials (DCCSM) (Grant: 09-067212) is gratefully acknowledged. Furthermore, the support from Oticon Foundation (Grant: 16-2166) to the first author for visiting Florida Atlantic University is gratefully acknowledged. The second and third author's research has been supported by NIA, EASA and ONR. The NIA program manager, Dr. Ronald Krueger, the EASA program manager, Dr. Simon Waite and the ONR program manager, Dr. Yapa Rajapakse showed keen interest in this project and is gracefully acknowledged.

\section{References}

1. Østergaard RC, Sørensen BF. Interface crack in sandwich specimen. Int J Fract 2007; 143: 301-316.

2. Kardomateas GA, Berggreen C, Carlsson LA. Energy-Release Rate and Mode Mixity of Face/Core Debonds in Sandwich Beams. AIAA J 2013; 51: 885-892.

3. Avilés F, Carlsson LA. Analysis of the sandwich DCB specimen for debond characterization. Eng Fract Mech 2008; 75: 153-168.

4. Carlsson LA, Gillespie Jr. JW. Mode-II interlaminar fracture of composites. Elsevier 
Sci Publ Appl Fract Mech to Compos Mater 1989; 113-157.

5. Li X and Carlsson LA. The Tilted Sandwich Debond (TSD) Specimen for Face/Core Interface Fracture Characterization. J Sandw Struct Mater 1999; 1: 60-75.

6. Quispitupa A, Berggreen C, Carlsson LA. Design Analysis of the Mixed Mode Bending Sandwich Specimen. J Sandw Struct Mater 2010; 12: 253-272.

7. Lu TJ, Xia ZC, Hutchinson JW. Delamination of beams under transverse shear and bending. Mater Sci Eng A 1994; 188: 103-112.

8. Li S, Wang J, Thouless MD. The effects of shear on delamination in layered materials. J Mech Phys Solids 2004; 52: 193-214.

9. Timoshenko S, Goodier JN. Theory of elasticity. New York: McGraw-Hill, 1970.

10. Barber JR. Intermediate Mechanics of Materials. Dordrecht: Springer Netherlands, 2011.

11. Andrews MG, Massabò R. The effects of shear and near tip deformations on energy release rate and mode mixity of edge-cracked orthotropic layers. Eng Fract Mech 2007; 74: 2700-2720.

12. Sørensen BF, Jørgensen K, Jacobsen TK, et al. DCB-specimen loaded with uneven 
bending moments. Int J Fract 2006; 141: 163-176.

13. Lundsgaard-Larsen C, Sørensen BF, Berggreen C, et al. A modified DCB sandwich specimen for measuring mixed-mode cohesive laws. Eng Fract Mech 2008; 75: 2514 2530.

14. Cantwell WJ, Davies P. A test technique for assessing core-skin adhesion in composite sandwich structures. J Mater Sci Lett 1994; 13: 203-205.

15. Ratcliffe JG, Reeder JR. Sizing a single cantilever beam specimen for characterizing facesheet-core debonding in sandwich structure. J Compos Mater 2011; 45: 26692684.

16. Rinker M, Ratcliffe JG, Adams DO, et al. Characterizing Face sheet/Core Disbonding in Honeycomb Core Sandwich Structure. NASA Technical Publication TP-2013-21 2013.

17. Ratcliffe J, Krueger R. Face Sheet/Core Disbonding in Sandwich Composite Components: A Road Map to Standardization: Test Method Development. In: 11th International Conference on Sandwich Structures. Dania Beach, Florida, 20 - 22 May, 2016. 
18. Kanninen MF. An augmented double cantilever beam model for studying crack propagation and arrest. Int J Fract; 9: 83-92.

19. Frostig Y, Baruch M, Vilnay O, et al. High-Order Theory for Sandwich-Beam Behavior with Transversely Flexible Core. J Eng Mech 1992; 118: 1026-1043.

20. Phan CN, Frostig Y, Kardomateas GA. Analysis of Sandwich Beams With a Compliant Core and With In-Plane Rigidity_Extended High-Order Sandwich Panel Theory Versus Elasticity. J Appl Mech 2012; 79: 41001.

21. Li X, Carlsson LA. Elastic Foundation Analysis of Tilted Sandwich Debond (TSD) Specimen. J Sandw Struct Mater 2000; 2: 3-32.

22. Weissman-Berman D, Petrie GL, Wang M. Flexural Response of Foam-Cored FRP Sandwich Panels. Soc Nav Archit Mar Eng 1988; 96.

23. Massabò R, Cavicchi A. Interaction effects of multiple damage mechanisms in composite sandwich beams subject to time dependent loading. Int J Solids Struct 2012; 49: 720-738.

24. Quispitupa A, Berggreen C, Carlsson LA. On the analysis of a mixed mode bending sandwich specimen for debond fracture characterization. Eng Fract Mech 2009; 76: 
594-613.

25. ANSYS ${ }^{\circledR}$ Mechanical User’s Guide. 2015.

26. Berggreen C, Simonsen BC, Borum KK. Experimental and Numerical Study of Interface Crack Propagation in Foam-cored Sandwich Beams. J Compos Mater 2006; 41: 493-520.

27. Hutchinson JW, Suo Z. Mixed Mode Cracking in Layered Materials. Adv Appl Mech 1991; 29: 63-191.

28. Sun CT, Pandey RK. Improved method for calculating strain energy release rate based on beam theory. AIAA J 1994; 32: 184-189.

29. Pandey RK, Sun CT. Calculating Strain Energy Release Rate in Cracked Orthotropic Beams. J Thermoplast Compos Mater 1996; 9: 381-395.

30. Wang J, Qiao P. Interface crack between two shear deformable elastic layers. $J$ Mech Phys Solids 2004; 52: 891-905.

31. Suo Z, Hutchinson JW. Interface crack between two elastic layers. Int J Fract 1990; 43: $1-18$.

32. Nilsson K-F, Asp LE, Alpman JE, et al. Delamination buckling and growth for 
delaminations at different depths in a slender composite panel. Int J Solids Struct 2001; 38: 3039-3071.

33. Bruno D, Greco F. Mixed mode delamination in plates: a refined approach. Int J Solids Struct 2001; 38: 9149-9177.

34. Anderson TL. Fracture Mechanics: Fundamentals and Applications. 3rd ed. Boca Raton: CRC Press, 2005.

35. He M-Y, Hutchinson JW. Kinking of a Crack Out of an Interface. J Appl Mech 1989; 56: $270-278$. 